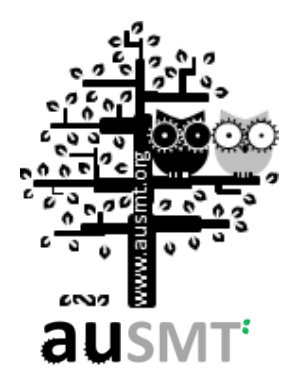

\title{
An Anatomy of Automation Business Opportunity in China in Times of High Wages: Taiwanese Businessmen Invested in China as a Case
}

\section{Ying-Mei Tai}

Industrial Economics and Knowledge Center, Industrial Technology Research Institute, Taiwan

(Received 3 October 2011; Published on line 1 December 2011)

Corresponding author: YMTai@itri.org.tw

DOI: 10.5875/ausmt.v1i2.114

\begin{abstract}
China's "The Twelfth Five-Year Plan" sets a tone to turn China "from a strong nation to a nation with wealthy people" in its national development policy. This policy is expected to increase hiring costs for foreign investors in China and indirectly creates potential business opportunities for automation. This research surveys a score of Taiwanese businessmen in China and finds their primary motivation for investing in China is to gain access to the labor force. A majority of Taiwanese factories have longer working hours. Their needs for automation are mainly in quality control and testing, information systems, and material handling and storage.
\end{abstract}

Keywords: Automation; Taiwanese Businesses; Investment; Foreign Investors; PRC

\section{Introduction}

China's rapid economic growth has propelled its gross domestic product (GDP) to increase from 21.63 trillion yuan in 2006 to 39.80 trillion yuan in 2010, jumping at an annual rate of $9.2 \%-14.2 \%$. In the same period, the cumulative growth rate reaches as high as $84 \%$. China has become the second largest economy in the world. Only the economy of the United States is larger. Nevertheless, China's average income per capita is less than one tenth of Japan, revealing the dilemma of blindly pursuing an excessively high growth rate in GDP.

China no longer emphasizes rapid GDP growth since the launch of the 12th Five-Year Plan in 2011. Rather, its focus has shifted from guaranteed growth to steady growth. Its objectives now are to readjust the economic structure and to optimize the livelihood of the entire society. For example, it intends to increase the income of the citizenry and narrow the gap between the rich and the poor. In other words, the new development policy aims to transform China "from a strong nation to a nation with wealthy people". The new policy approach will create a burden for foreign investors in China by increasing labor costs but, as a consequence, will drive up the demand for automation systems.

This research targeted Taiwanese businessmen in mainland China. Methodologies such as personal interviews, questionnaire surveys, and expert symposia were used. Research results indicate that the primary motivation for setting up production bases in China was to acquire manpower. A majority of Taiwanese factories in China are running longer work times. With longer working hours, they are able to effectively shorten the payback period of automation investment, which bodes well for automation system manufacturers. Quality control and testing, information systems, and material handling and storage are the main categories they need in automation.

\section{Methodology}

Automation, a cross-disciplinary integration technology, is the use of energy sources, aside from animal power, to replace human power, including mental 
ability and physical vigor, in operating, controlling, and monitoring facilities or programs. This research limits its scope to automation in the manufacturing industry. Based on user's types of demand, it breaks automation into seven categories: Major processing, assembly, surface treatment, material handling and storage, quality control, production management, and information systems. The survey was conducted through personal interviews, questionnaires, and expert symposia to obtain primary data, coupled with secondary data from newspapers, magazines, industrial reports, professional websites, and databases, in the hope of revealing the general profile of the automation market in China. Details are illustrated below:

\section{Personal Interviews}

The design and revision of the questionnaire used in this research was based on experts' opinions obtained through repetitive consultation with technicians at the Mechanical and System Research Laboratories, Industrial Technology Research Institute (MSRL/ITRI). An early draft of the questionnaire was rounded off after pre-tests on three manufacturers who use automation systems in their facilities in China, as listed in [1].

In addition, the research team visited 11 manufacturers with automation systems in China. They include $3 \mathrm{C}$ (consumer electronic, computer, and communication) product assemblers, electronic parts and components manufacturers, vehicle parts and components manufacturers, and other manufacturers, as shown in [2]. The purpose of the interviews was to find out the facts about their needs for automation, their main considerations in procuring automation systems, and their assessment of automation equipment produced by a variety of countries.

\section{Questionnaire Survey}

The study surveyed Taiwanese companies in China who are members of the Taiwan Electrical and Electronic Manufacturers' Association (TEEMA) and who gained approval from the Investment Commission of the Ministry of Economic Affairs (MOEA) to invest in China. Companies surveyed are located in eastern and southern China where the highest density of investment has taken place. A total of 1,570 questionnaires were distributed

Ying-Mei Tai is a Researcher in the Machinery \& System Research Division at Industrial Economics and Knowledge Center, also a Ph.D Candidate in Dept. of Business Administration in School of Management at National Yunlin University of Science and Technology (Taiwan). Her Research Topics Focus on Machine Tools, Plastic Machinery, Automobiles, Bicycle, Electric Vehicles, and so on. and 95 effective samples were retrieved, registering a response rate of $6.1 \%$.

\section{Expert Symposium}

A symposium was organized and seven experts representing industry, academia, and research institutes were invited to discuss the accuracy of the survey, to clarify all doubts, and to assure that the final results actually reveal the practical implications for automation.

\section{Secondary Data}

This study gathers secondary data extensively from newspapers, magazines, industrial reports, professional websites, and databases to make up for the width and completeness that the primary data did not provide.

\section{Findings}

The study begins with a general description of the automation market in China, followed by a presentation of the findings of the survey, including primary motivations behind investment, work shift systems, and demands for automation.

\section{Analysis of Automation Market in China}

According to the China Industrial Control Website (www.gongkong.com), the automation market in China hit 94.3 billion yuan in 2010. This represents a growth rate of $26.6 \%$ from the previous year, when the automation market was 74.5 billion yuan. This increase was due to the recovery in machinery equipment and increasing demand from city governments, the mining industry, the chemical industry, and the hydro industry. It is forecasted that the market will enjoy double-digit growth in the next three years, reaching 108.4 billion yuan in 2011 (15.0\% growth), 121.5 billion yuan (12.1\% growth) in 2012, and 133.6 billion yuan (10.0\% growth) in 2013, respectively. During this period, the accumulated growth comes close to $80 \%$, making China an important market for the global automation industry, as shown in Figure 1.

Of the 94.3 billion yuan in 2010, transmission systems, as represented by low-voltage converters, take the lion's share, followed by sensors and meters. Geographically, East China, which is the most prosperous region in China and home to the greatest number of competitive manufacturers of all kinds, received the largest share. It had a market size of 41.17 billion yuan, 


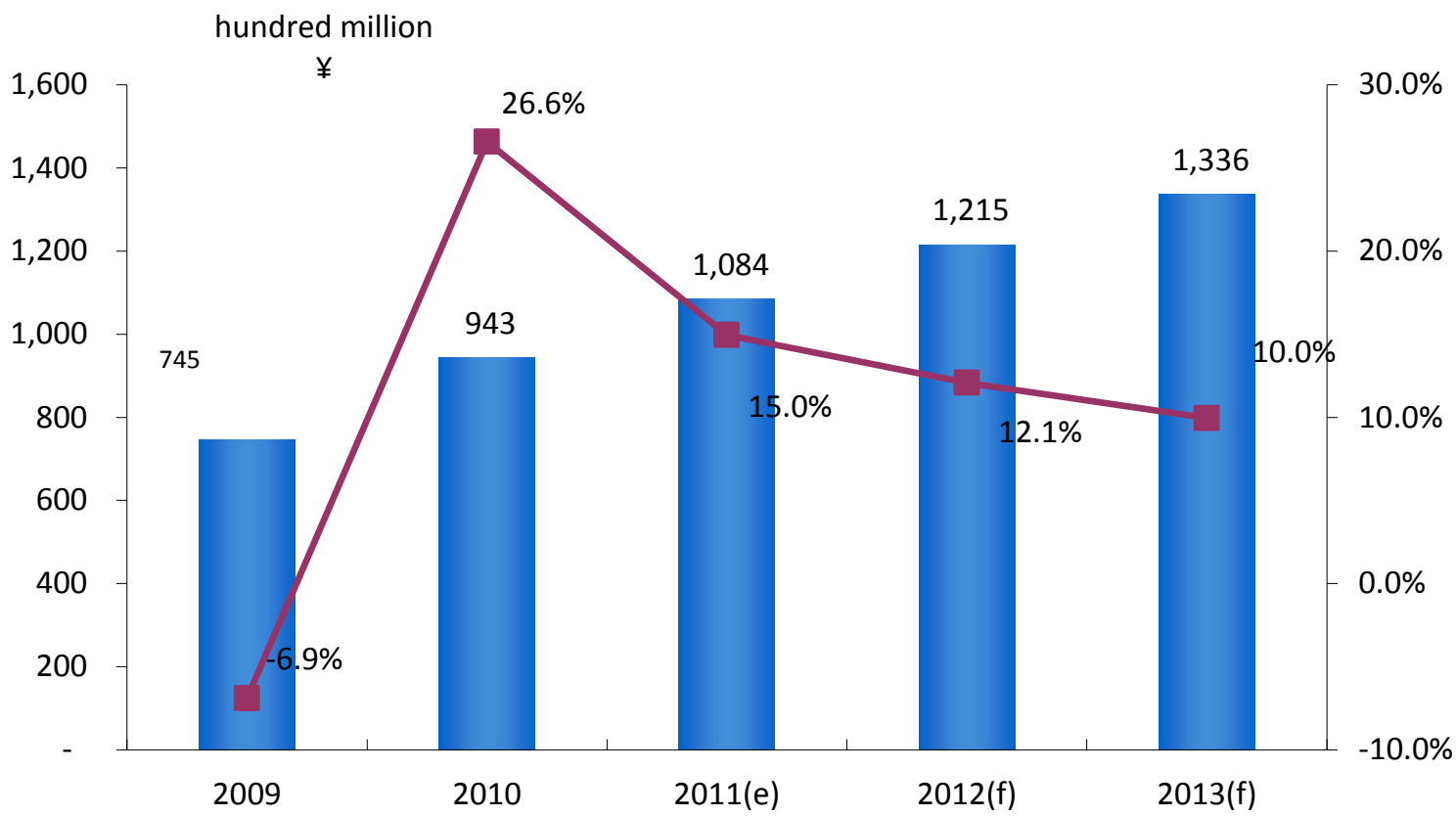

Figure 1. Automation Market in China. Note: Data of 2011, 2012, and 2013 are forecasted numbers. [3]

Table 1. 2010 Automation Market in China by product and region. [3] (Unit: in Million Yuan)

\begin{tabular}{|l|l|l|l|l|l|l|l|}
\hline Region & $\begin{array}{l}\text { Transmission } \\
\text { System }\end{array}$ & $\begin{array}{l}\text { Sensors } \\
\text { and } \\
\text { Meters }\end{array}$ & $\begin{array}{l}\text { Control } \\
\text { System }\end{array}$ & Actuator & $\begin{array}{l}\text { Motion } \\
\text { System }\end{array}$ & Miscellaneous & Total \\
\hline East & 10,871 & 7,562 & 7,685 & 6,958 & 5,991 & 2,104 & 41,171 \\
\hline South & 5,078 & 4,048 & 3,891 & 3,161 & 2,250 & 959 & 19,387 \\
\hline North & 3,592 & 2,498 & 2,099 & 1,699 & 1,062 & 548 & 11,498 \\
\hline Northeast & 3,152 & 1,915 & 1,516 & 1,486 & 2,288 & 430 & 10,787 \\
\hline Southwest & 1,890 & 1,228 & 1,091 & 826 & 905 & 240 & 6,180 \\
\hline Northwest & 1,766 & 1,064 & 718 & 749 & 804 & 218 & 5,319 \\
\hline Total & 26,349 & 18,315 & 17,000 & 14,879 & 13,300 & 4,499 & 94,342 \\
\hline
\end{tabular}

representing $43.6 \%$ of the entire China market. This provided business opportunities for all types of equipment, and in turn for automation providers. Textile machinery, plastic machinery, elevators, cranes, and air conditioners each accounted for more than $60 \%$ of the domestic market in their own product categories, while printing machinery, electronic equipment, and packaging machinery accounted for $50 \%$ of the domestic market in their product categories.

South China ranks second in geographical terms, with a market size of 19.39 trillion yuan and a $20.5 \%$ share of the domestic market. The main demands in this region are paper machinery, packaging machinery, power supply equipment, and electronic equipment, each accounting for approximately $30 \%$ of market share. Other regions have less market share. North China has $12.2 \%$,
Northeast China stands at $11.4 \%$, and Northwest China records 5.6\%, as summarized in Table 1.

\section{Analysis of Demand for Automation by Taiwanese Businesses in China}

This study assessed the demand for automation by Taiwan businesses on the mainland, as well as the motivations behind their investments, and the way they organize the work shifts of their employees as illustrated below:

(1) Investment Motivation

Based on the 95 questionnaires retrieved, 62 manufacturers, or $65 \%$ of the respondents, say that their 
primary motivation for investment in China is to take advantage of the labor force. This is followed by 61 manufacturers, or $61 \%$ of the respondents, who state that their main purpose is to expand into the China market. Additional reasons cited for investing in China, although with less frequency, are land use and similar culture and language backgrounds. Please see Figure 2.

\section{(2) Work Shifts}

Forty-two percent of the respondents have adopted a two-shift operation, while $34 \%$ embrace a mix of one shift and routine overtime work. Firms that fall into these two types of production arrangement make up more than three quarters of the respondents, signaling that long working hours are common in Taiwanese factories in China. This phenomenon has something to do with the fact that a majority of the respondents are manufacturers of electronic parts and components, computers, electronic products, and optical products. Some of their products have life cycles as short as three to six months. The manufacturers are forced to speed up their production so as to win as much business as possible. Longer working hours help trim off the payback period of automation investment, which is conducive to automation system suppliers in expanding markets.

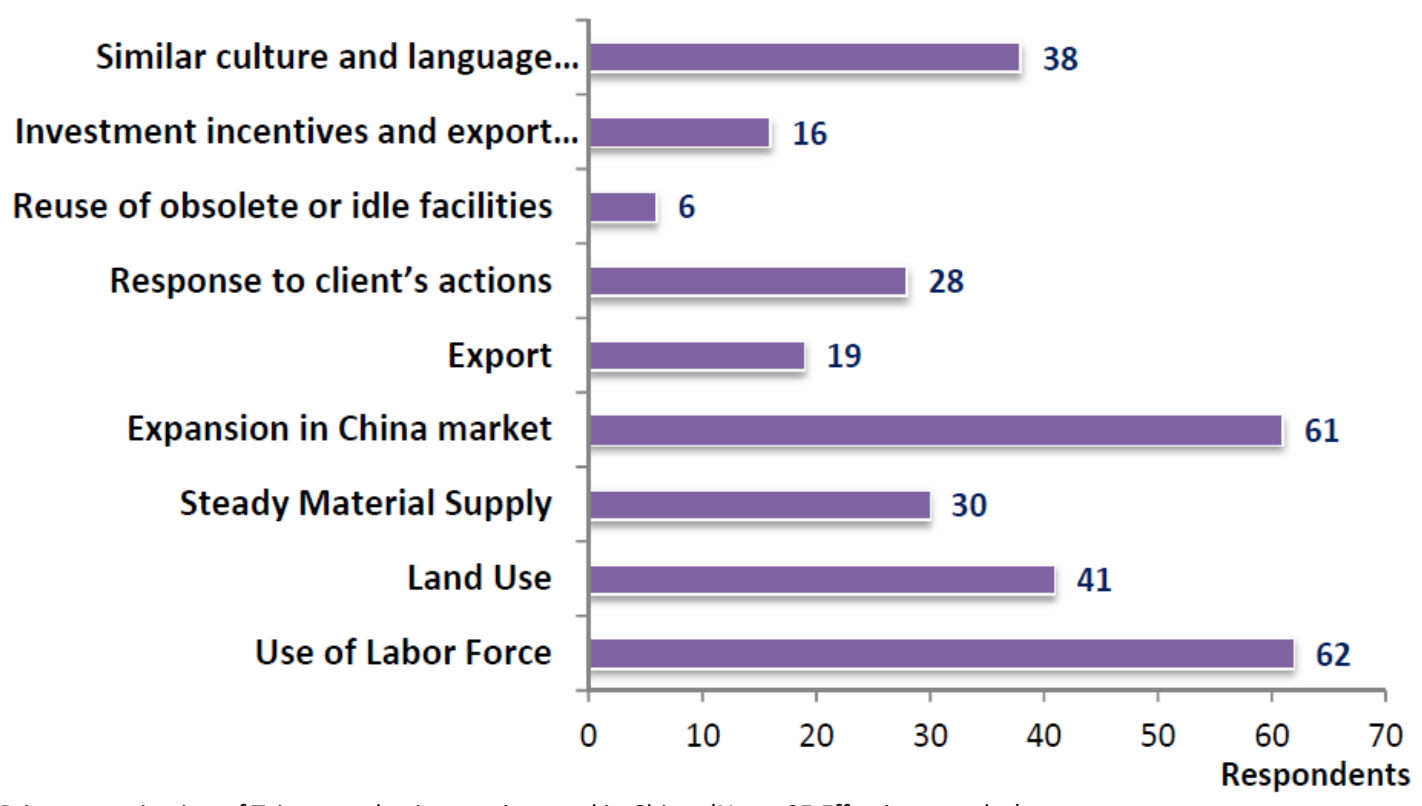

Figure 2. Primary motivation of Taiwanese businesses invested in China. (Note: 95 Effective samples)

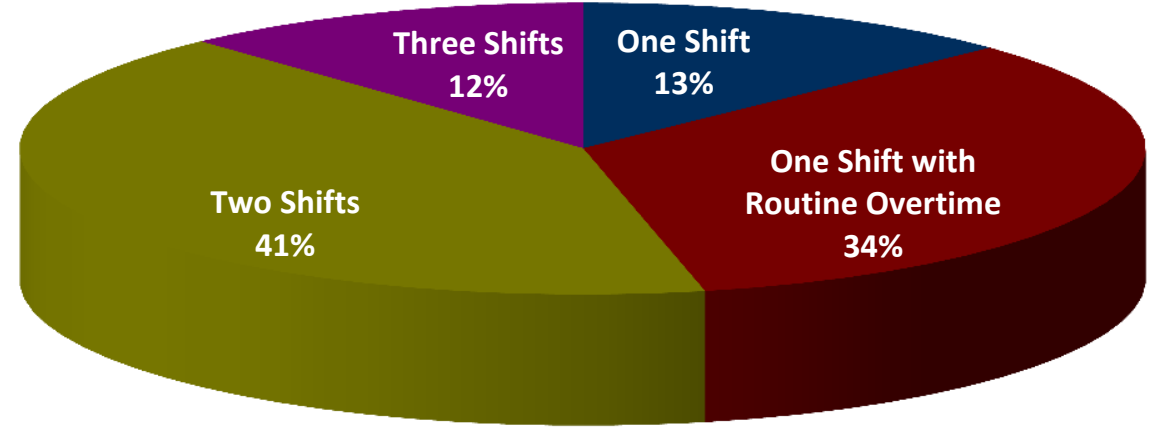

Figure 3. Work shifts distribution of Taiwanese businesses in China. (Note: Effective sample size is 95 and percentage is the ratio of responsive samples over effective samples) 
(3) Automation Demand Details

The 95 questionnaires retrieved show quality control and testing had the highest level of demand for automation, with an average score of 3.3 out of 5 . Other demands for automation, with scores of 3.1 to 3.3, occurred in the areas of production management information systems, CAD/CAE, plant surveillance of temperature, pressure, processing speed, and formula of raw material input. This is because China has become the factory of the world, and the world's top manufacturers cluster there accordingly. Quality control and testing systems, as well as information systems, could strengthen the competitiveness of those who adopt them. In addition automation related to putting workpieces on and off production lines, transportation, packaging, palletization and warehousing are in considerable demand, scoring 3.0 to 3.1. These operations rely heavily on machinery because they cannot easily be handled by people.

Processing work (including cutting, shaping, special industrial processing, and laser processing), assembling (including adhesives application, spot welding, arc welding, screw locking, embedding, and layout), and surface treatment (including painting, spray painting, finishing, deburring, and coating) have relatively low scores, as indicated in figure 4.

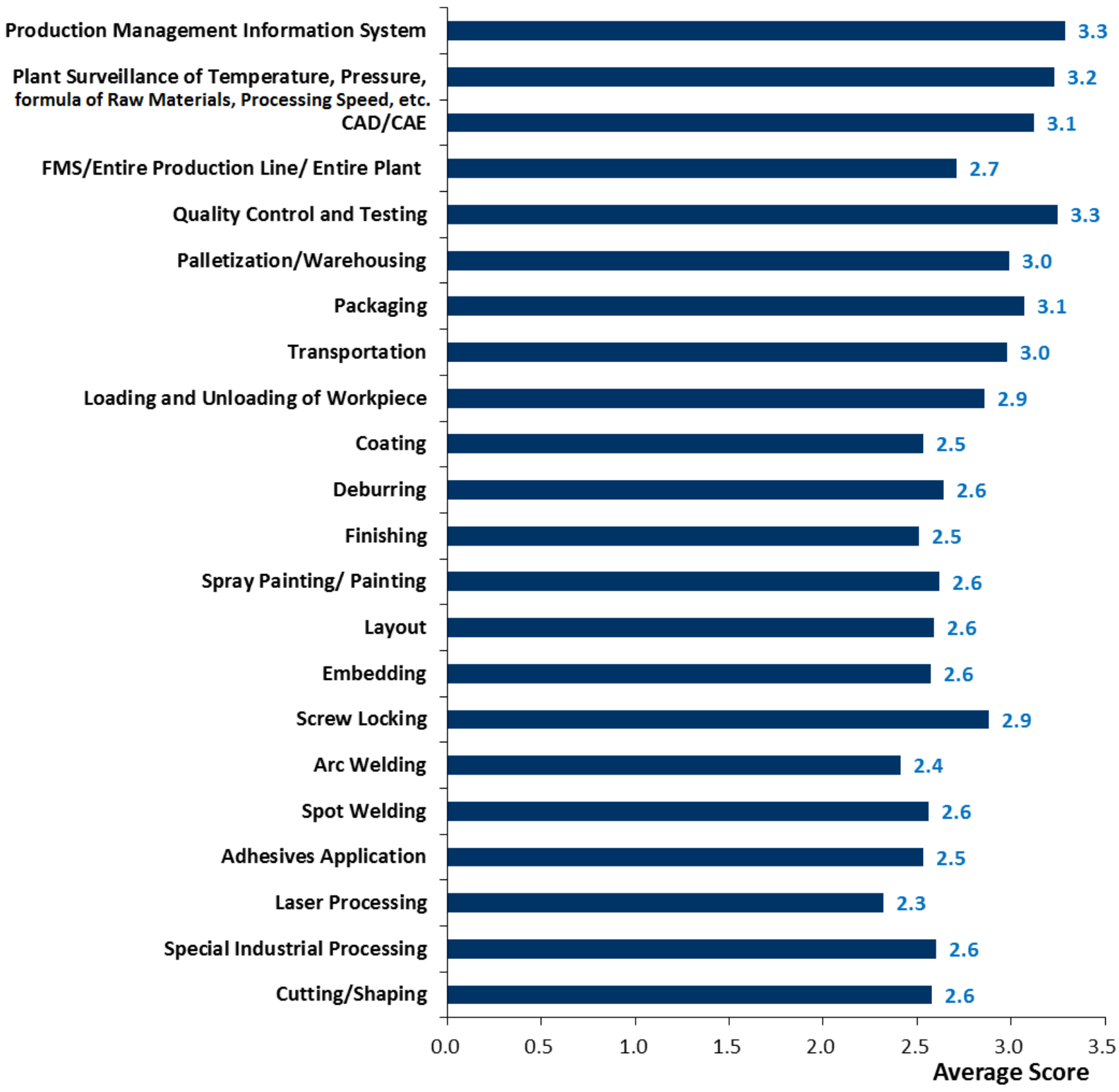

Figure 4. Demand for automation by Taiwanese businesses in China. (Note: Effective sample size is 95; 1 being "very low", 2 being "low", 3 being "normal", 4 being "high", and 5 being "very high") 


\section{Conclusion}

Years of rapid economic growth have catapulted China to become the world's second largest economy. Its "Twelfth Five-Year Plan" is expected to increase wages in China and prospects for the automation market look promising as a result.

This research finds that acquiring cheap and abundant labor is the main inducement for Taiwan businesses to invest on the other side of the Strait. On the average, Taiwanese factories in China have longer working hours, which in fact cuts short the payback period of automation investment, opening up more business opportunities for automation system providers. Taiwanese businesses' main demands for automation systems lie in the areas of quality control and testing, information systems, and material handling and storage. Automation covers a wide range of categories and may vary considerably in different industries. Limited by time and budget, this research conducts a preliminary probe into the general demand for automation by Taiwanese businesses in China. Follow-up research is advised to focus on industries in greater demand of automation, such as the $3 \mathrm{C}$ and transportation industries, so that their needs for automation can be adequately understood.

\section{References}

[1] China Statistical Yearbook - 2010. Beijing, China China Statistics Press, 2010.

[2] Automation Engineering, 1st ed. Taipei, Taiwan: Gau Lih Book co., 1993.

[3] "China's Automation Market Assessment Reports," Gongkong Information Technology Co., Ltd., Beijing, China, 2010. 